\title{
Emerging Scholar Best Article Award, 2016
}

\author{
Roger J. R. Levesque ${ }^{1}$
}

Received: 26 September 2016 / Accepted: 28 September 2016 / Published online: 6 October 2016

(C) Springer Science+Business Media New York 2016

The editors of the Journal of Youth and Adolescence are very pleased to announce the 2016 recipient of its Emerging Scholar Best Article Award. This award goes to the article's lead author, who must be an "emerging scholar" (i.e., an untenured researcher, such as a graduate student, postdoctoral scholar, research scientist, or assistant professor). The recipient of the award is selected by a random group of editorial board members who evaluate manuscripts' innovative and substantive contributions to the empirical understanding of adolescence. In addition to receiving the recognition from colleagues, the winner receives a financial award generously provided by Springer, the journal's publisher.

The 2016 winner is Wendi L. Johnson, for her article entitled "The Age-IPV Curve: Changes in the Perpetration of Intimate Partner Violence During Adolescence and Young Adulthood," which was co-authored with Peggy C. Giordano, Wendy D. Manning, and Monica A. Longmore (Johnson et al. 2015). Her study focused on how intimate partner violence develops over adolescence and young adulthood, while other studies generally have focused on victimization with less attention to temporal shifts in perpetration. Drawing on five waves of data from the Toledo Adolescent Relationships Study (TARS), she and her colleagues examined patterns of the perpetration of intimate partner violence among a large $(N=1164 ; 51.1 \%$ female $)$ and diverse $(63.9 \%$ non-Hispanic White, $24.6 \%$ nonHispanic Black, $11.5 \%$ Hispanic) sample of adolescents

Roger J. R. Levesque

rlevesqu@indiana.edu

Indiana University, 302 Sycamore Hall, Bloomington, IN, USA and young adults (spanning the ages of 13-28 years). They demonstrated that intimate violence patterns deviate from the age-crime curve, with women's involvement in intimate violence increasing and their involvement in other antisocial behaviors decreasing. In addition, their study examined traditional behavioral and psychological risk factors for violence, such as delinquency, alcohol and drug use, and depressive symptoms. The factors accounted for some of the age variation for men but not women. For both male and female youth, however, their study found that a substantial proportion of the risk for the perpetration of intimate violence was accounted by relationship risk factors, such as the frequency of disagreements, trust, jealousy, validation and self-disclosure. Their findings support calls for focusing on the development and maintenance of healthy relationships in efforts to address intimate partner violence.

The editors view receiving the award as a considerably distinctive accomplishment. The journal publishes 12 issues per year, each typically containing about 16 manuscripts. In addition, it is notable that, every year, more and more first authors no longer are emerging scholars. This means that there are fewer who can qualify to be considered, which may seem as making the award less competitive. But, but this development actually makes the process even more competitive for emerging scholars, as they have increased competition to get published in the journal in the first place.

The Editors select the award recipient through a two-step process. The first involves identifying all articles with first authors who are emerging scholars and then selecting the strongest article from each journal issue. The second step involves another group of editors who rank the selected articles.

The process resulted in a pool of very impressive articles. This is similar to prior years (see Levesque 2011, 2012, 
2013, 2014, 2015a). Unlike prior years, however, there appears to be much less variation in the range of topics that emerged. The vast majority focused on problem behavior, such as conduct problems (Buil et al. 2015), intimate partner violence (Johnson et al. 2015 ), delinquency (Meldrum et al. 2015), feelings of safety (Côté-Lussier et al. 2015), behavioral problems (Vaughan et al. 2015), impulse control (Shulman 2015) as well as drug and alcohol use (Abar et al. 2015; Fish and Pasley 2015; Ehrenreich et al. 2015; TannerSmith et al. 2015). In fact, only two articles did not fall in that general focus: one article examined biological stress (Cook et al. 2015) and another character development (Wang et al. 2015). Yet, focusing on the general topics of the manuscripts, however, would miss one of their most important aspects. The studies are marked by increasing complexity, particularly in the number of factors that they address to help ensure robustness and replicability (see Levesque 2015b, 2016).

On behalf of the editorial board, I again would like to congratulate Wendi L. Johnson and her colleagues for their success. Their recognition comes at a remarkable time in the growth of our journal and field.

\section{Compliance with Ethical Standards}

Conflict of Interest The authors declare that they have no competing interests.

\section{References}

Abar, C. C., Jackson, K. M., Colby, S. M., \& Barnett, N. P. (2015). Parent-child discrepancies in reports of parental monitoring and their relationship to adolescent alcohol-related behaviors. Journal of Youth and Adolescence, 44(9), 1688-1701.

Buil, J. M., Koot, H. M., Olthof, T., Nelson, K. A., \& Lier, P. A. (2015). DRD4 genotype and the developmental link of peer social preference with conduct problems and prosocial behavior across ages 9-12 years. Journal of Youth and Adolescence, 44(7), 1360-1378.

Cook, E. C., Chaplin, T. M., \& Stroud, L. R. (2015). The relationship between autonomy and relatedness and adolescents' adrenocortical and cardiovascular stress response. Journal of Youth and Adolescence, 44(11), 1999-2011.

Côté-Lussier, C., Barnett, T. A., Kestens, Y., Tu, M. T., \& Séguin, L. (2015). The role of the residential neighborhood in linking youths' family poverty trajectory to decreased feelings of safety at school. Journal of Youth and Adolescence, 44(6), 1194-1207.
Ehrenreich, H., Nahapetyan, L., Orpinas, P., \& Song, X. (2015). Marijuana use from middle to high school: co-occurring problem behaviors, teacher-rated academic skills and sixth-grade predictors. Journal of Youth and Adolescence, 44(10), 1929-1940.

Fish, J. N., \& Pasley, K. (2015). Sexual (minority) trajectories, mental health, and alcohol use: a longitudinal study of youth as they transition to adulthood. Journal of Youth and Adolescence, 44(8), $1508-1527$.

Johnson, W. L., Giordano, P. C., Manning, W. D., \& Longmore, M. A. (2015). The age-IPV curve: changes in the perpetration of intimate partner violence during adolescence and young adulthood. Journal of Youth and Adolescence, 44(3), 708-726.

Levesque, R. J. R. (2011). Emerging scholar best article award, 2011. Journal of Youth and Adolescence, 40, 565-1567.

Levesque, R. J. R. (2012). Emerging scholar best article award, 2012. Journal of Youth and Adolescence, 41, 1557-1559.

Levesque, R. J. R. (2013). Emerging scholar best article award, 2013. Journal of Youth and Adolescence, 42, 1910-1912.

Levesque, R. J. R. (2014). Emerging scholar best article award, 2014. Journal of Youth and Adolescence, 43, 2091-2092.

Levesque, R. J. R. (2015a). Emerging scholar best article award, 2015. Journal of Youth and Adolescence, 44, 2395-2396.

Levesque, R. J. R. (2015b). Statistical guidelines for publishing in the journal of youth and adolescence. Journal of Youth and Adolescence, 44(12), 2391-2394.

Levesque, R. J. R. (2016). Reviews in research on adolescence: Genres, trends, and challenges. Adolescent Research Review, 1(1), 3-13.

Meldrum, R. C., Barnes, J. C., \& Hay, C. (2015). Sleep deprivation, low self-control, and delinquency: A test of the strength model of self-control. Journal of Youth and Adolescence, 44(2), 465-477.

Shulman, E. P., Harden, K. P., Chein, J. M., \& Steinberg, L. (2015). Sex differences in the developmental trajectories of impulse control and sensation-seeking from early adolescence to early adulthood. Journal of Youth and Adolescence, 44(1), 1-17.

Tanner-Smith, E. E., Steinka-Fry, K. T., Hennessy, E. A., Lipsey, M. W., \& Winters, K. C. (2015). Can brief alcohol interventions for youth also address concurrent illicit drug use? Results from a meta-analysis. Journal of Youth and Adolescence, 44(5), 1011-1023.

Vaughan, E. B., Van Hulle, C. A., Beasley, W. H., Rodgers, J. L., \& D'Onofrio, B. M. (2015). Clarifying the associations between age at menarche and adolescent emotional and behavioral problems. Journal of Youth and Adolescence, 44(4), 922-939.

Wang, J., Ferris, K. A., Hershberg, R. M., \& Lerner, R. M. (2015). Developmental trajectories of youth character: A five-wave longitudinal study of Cub Scouts and non-Scout boys. Journal of Youth and Adolescence, 44(12), 2359-2373.

Roger J. R. Levesque is Professor of Criminal Justice and (Affiliate) Law, Indiana University. He serves as Editor-in-Chief of the Journal of Youth and Adolescence and the Adolescent Research Review. 